\title{
Cancer-related fatigue: trigger factors and function of exercise
}

\author{
Aida Tórtola-Navarro', Alfredo Santalla² \\ ${ }^{\prime}$ Facultad de Ciencias de la Salud. Universidad Isabel I. 2Universidad Pablo de Olavide. Departamento de Deportes e Informática.
}

doi: 10.18176/archmeddeporte.00045

Received: $19 / 06 / 2020$

Accepted: 25/02/2021

Key words:

Cancer-related fatigue. Exhaustion. Tiredness. Therapeutic exercise.

\section{Summary}

Introduction: Several publications have theorized about the triggers of cancer-related fatigue, one of the side effects of the disease and its treatments that most stress cancer survivors. On the other hand, physical exercise has been analyzed as a therapy to reduce the impact of this sequel, and several institutions support its inclusion within care programs for the oncological population. However, cancer fatigue and the role that exercise plays in its control has been exposed without an overall assessment that shows its complexity and why physical exercise is so valuable to reducing it.

Objectives: The objective of this work was to review the existing evidence about triggers of fatigue in cancer, to expose how physical exercise acts on each of them to control their symptoms and achieve a comprehensive therapeutic effect.

Material and method: Several bibliographic searches were carried out to find out which were the triggers of fatigue proposed by the research, how they develop and affect the oncological patient and, finally, to what extent physical exercise would be a viable tool to control its effects.

Results: Exposed to more than twenty triggers and aggravating factors of cancer-related fatigue, we found that most of them could be prevented or at least controlled through physical exercise.

Conclusions: It is impossible to isolate some triggers from others, and some of them are inevitable as they are part of the medical treatment of the disease. Understanding the relationships between triggers and knowing the positive effects of physical exercise on each one of them is clearly useful to control this side effect.

\section{Fatiga relativa al cáncer: factores desencadenantes y función del ejercicio físico}

\section{Resumen}

Introducción: Diversas publicaciones han teorizado sobre los desencadenantes de la fatiga relativa al cáncer, uno de los efectos secundarios de la enfermedad y sus tratamientos que más estresa a los supervivientes de esa enfermedad. Por otro lado, el ejercicio físico ha sido analizado como terapia para reducir el impacto de esta secuela, y diversas instituciones apoyan su inclusión dentro de los programas de cuidado para población oncológica. No obstante, la fatiga en cáncer y el papel que el entrenamiento tiene para su control, se ha expuesto sin realizar una valoración global que muestre su complejidad y por qué el ejercicio físico resulta de tanto valor para reducirla.

Objetivos: El objetivo de este trabajo fue revisar la evidencia existente sobre los desencadenantes de fatiga en cáncer, para exponer en qué modo el ejercicio físico actúa sobre cada uno de ellos para controlar su sintomatología y conseguir un efecto terapéutico integral.

Material y método: Se realizaron diversas búsquedas bibliográficas que permitieran conocer cuáles eran los desencadenantes de fatiga propuestos por la investigación, cómo se desarrollan y afectan al paciente oncológico y, por último, en qué grado el ejercicio físico sería una herramienta viable para controlar sus efectos.

Resultados: Expuestos más de una veintena de desencadenantes y agravantes de la fatiga relativa al cáncer, encontramos que la mayoría de ellos podrían ser prevenidos o al menos controlados a través del ejercicio físico.

Palabras clave:

Fatiga relativa al cáncer. Cansancio. Astenia. Ejercicio terapéutico.
Conclusiones: Resulta imposible aislar unos desencadenantes de otros, existiendo, además, algunos de ellos que son inevitables al ser parte del tratamiento médico de la enfermedad. Entender las relaciones que se producen entre desencadenantes y conocer los efectos positivos del ejercicio físico sobre cada uno de ellos, es claramente útil para controlar este efecto secundario. 


\section{Introduction}

Defined as a distressing, persistent, subjective sense of physical, emotional, and/or cognitive tiredness' ${ }^{1}$, cancer-related fatigue (CRF) is one of the consequences of the disease and its treatment which most distresses survivors ${ }^{1-3}$. Its pathophysiology is multifactorial, and the trigger factors proposed include: psychological disturbances, endocrine and energy metabolism dysfunctions, pain, pro-inflammatory cytokine production, and rheumatic complications ${ }^{2-5}$.

The treatments to reduce CRF include both pharmacological and non-pharmacological interventions ${ }^{1}$. Of the latter, physical exercise (PE) has proven effective for reducing $\mathrm{CRF}^{4-6}$ and is, compared with psychosocial therapies, the type of non-pharmacological intervention which leads to the greatest improvement during cancer treatment, which is precisely when CRF is at its most intense ${ }^{7}$. For some authors, PE affects fatigue because it improves one of its triggers, thereby reducing the overall intensity of the fatigue 8 . Many of the studies conducted have analysed the level of CRF in relation to variables such as the level of muscle strength ${ }^{6}$, inflammatory markers ${ }^{9}$, anaemia ${ }^{10}$, and cardiovascular capacity ${ }^{11}$.

The aim of this paper is to provide a narrative review of the evidence of reducing CRF through $\mathrm{PE}$, analysing each trigger factor, its individual influence on the other factors, and the therapeutic effect of PE on each.

\section{Materials and method}

Three independent literature searches were carried out on the PubMed, Google Scholar, Springer Link, SCiELO, and Dialnet databases. In the first search, the terms used were Cancer-Related Fatigue and similar (fatigue cancer, oncologicfatigue), selecting those publications containing information on its pathophysiology, symptoms, and/or trigger factors.

Secondly, a search was made to select publications describing each CRF trigger factor and its symptoms in cancer populations. Research conducted on healthy populations was also analysed in order to further study certain trigger factors which have not been studied too much in relation to cancer. Those sources which did not provide information on the development, physiological processes, and symptoms of the proposed trigger factors were excluded.

Finally, those publications analysing physical exercise as a tool to mitigate CRF or improve any of its trigger factors were reviewed, selecting those research and review papers giving results on the level of fatigue in cancer patients or survivors.

\section{Results}

Figure $1 \mathrm{~A}$ shows the CRF triggers described in the literature and the direct relationships between them. On the $Y$ axis, they are ordered from most to least influential on other trigger factors; and on the $X$ axis, from least to most affected by other CRF factors. So, for example, chemotherapy is the first trigger factor on the $Y$ axis, because it leads to alterations in more factors, but it is in eighth place on the $X$ axis, because only three trigger factors can influence it. As can be seen, on average, each trigger factor is directly related to another seven, either because it affects them or is influenced by them. Those trigger factors whose degree of relationship is greater than this average are highlighted in Figure $1 \mathrm{~A}$.

Beyond direct relationships, trigger factors may also have indirect effects on other triggers. For example, Figure 1B shows not only the relationship between chemotherapy and nutritional problems (direct) but also how psycho-emotional complications could potentially affect the treatment by worsening the nutritional condition of the patient (indirect).

Of the trigger factors with the greatest impact, some are inevitable, such as treatment, and others are difficult to tackle. So, knowing the effects of PE on each trigger factor provides a perspective on the therapeutic potential of exercise on CRF.

\section{Decreased activity and physical deconditioning}

Because they are also key factors in the development of chronic fatigue, it has been suggested that decreased activity and the consequent drop in fitness are precursors to $\mathrm{CRF}^{8}$. It has been observed that decreased activity in breast cancer survivors (BCS) contributes to the development of osteoporosis ${ }^{12}$, poorer cardiovascular health ${ }^{13}$, and the loss of muscle mass and strength ${ }^{12,14}$, thus aggravating $\mathrm{CRF}^{3}$.

The research conducted on the effects of physical exercise on these trigger factors argues that exercise is associated with a higher level of non-sporting activity both during and after treatment ${ }^{15}$, and can also induce further improvements in up to ten CRF triggers. Nevertheless, there are still barriers to cancer survivors (CS) acquiring exercise-related habits ${ }^{16,17}$. On the one hand, patients are faced with external limitations, such as a lack of information and advice on what exercise they can do, and at what intensity they can do it ${ }^{16}$. On the other, patients are also limited by intrinsic factors, such as muscle and joint pain, fatigue itself, the side effects specific to the type of cancer $^{16}$, and not having enough time ${ }^{17}$.

\section{Organ dysfunctions}

The main organ dysfunctions related to cancer are cardiac, pulmonary, renal and hepatic dysfunctions. These are related to other CRF triggers in varying degrees.

- Heart conditions: The cardiovascular system can be affected by physical deconditioning ${ }^{18}$, weight gain ${ }^{19}$, dysfunctions in other organs $^{20}$, and treatment ${ }^{18,19}$. This type of condition is a major risk in CS and is, in fact, the leading cause of death in CS aged 65 and over ${ }^{21}$.

- Lung conditions: Radiotherapy to the chest influences the development of pulmonary complications, with an increased risk of developing pulmonary fibrosis, pneumonitis, and alterations of the respiratory function ${ }^{22}$. In the case of chemotherapy, the mani- 
Figure 1. Interactions between cancer-related fatigue triggers.

\section{$1 \mathrm{~A}$}

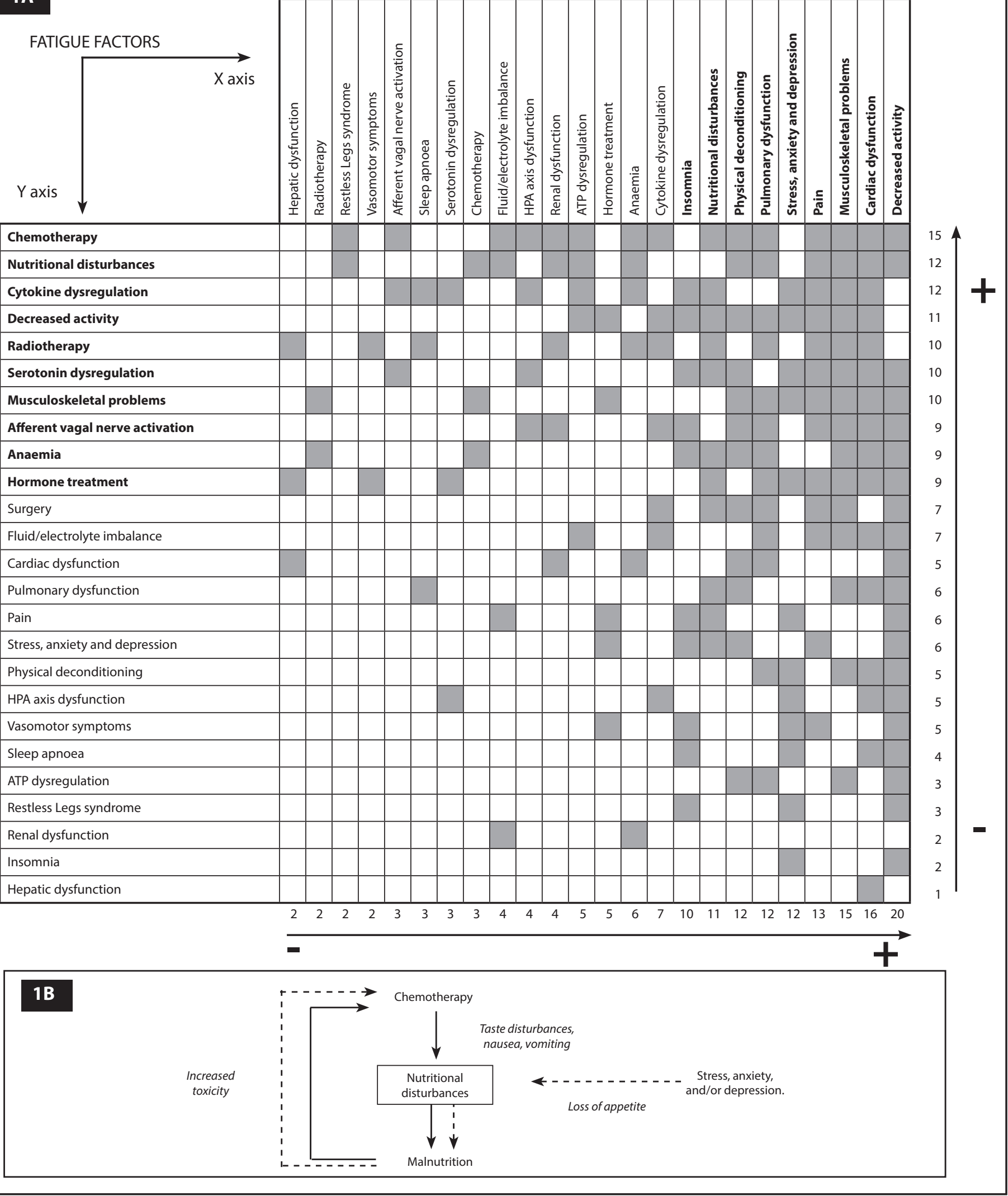


festations of toxicity are often delayed and come with coughing, fever, and fatigue ${ }^{23}$.

- Kidney and liver conditions: The kidneys, which are key to eliminating the drugs used in chemotherapy, are exposed to the risk of renal failure, nephrotic syndrome, and tubulopathies ${ }^{23}$. Similarly, radiotherapy can produce acute hyporeninaemic hypertension and nephropathy ${ }^{22}$. Chemotherapy is not considered problematic for the liver unless the patient has a previous condition ${ }^{23}$. However, radiotherapy can alter the values of transaminases and liver disease markers such as gamma-glutamyl transpeptidase ${ }^{22}$.

Although PE is part of rehabilitation therapies for different cardiopulmonary conditions, in cancer its use has not yet been standardised ${ }^{11}$. However, the general consensus is that PE is safe and tolerable for $\mathrm{CS}^{11,19}$, and PE programmes with BCS have been observed to produce improvements in cardiovascular efficiency , $11^{11}$ and blood circulation, and reductions in cholesterol levels, blood pressure ${ }^{24}$, attendant symptoms (including CRF), and risk of mortality from all causes ${ }^{11}$.

Similarly, PE has proven effective in increasing maximal oxygen consumption $\left(\mathrm{VO}_{2 \max }\right)$ both during and after chemotherapy in patients with Hodgkin lymphoma ${ }^{25}$, breast cancer ${ }^{26}$, and solid tumours, even when being treated for anaemia ${ }^{27}$. Nevertheless, it is yet to be demonstrated whether PE acts on other cardiovascular health markers ${ }^{11,19}$, such as cardiac output, the differences in oxygen content between venous and arterial blood, or defects in oxygen pathways ${ }^{11}$.

\section{Musculoskeletal problems}

- Cancer cachexia: Although some authors state that a reduction in fatty tissue does not necessarily accompany cancer cachexia, there is a loss of muscle tissue, associated with a lower tolerance to the treatment, a reduction in the effectiveness of the treatment, and loss of quality of life $(\mathrm{QOL})^{28}$. The cachectic state is particularly serious because it is very difficult to reverse through conventional nutritional support ${ }^{28,29}$. Cachexia is usually accompanied by anaemia, fatigue, and malnutrition ${ }^{30}$, affecting protein metabolism ${ }^{30,31}$ and, therefore, the possibility of ATP regeneration ${ }^{31}$. It is also associated with the development of osteoporosis ${ }^{32}$ and can induce cardiac atrophy and dysfunction ${ }^{33}$.

- Bone loss: Bone health is especially important for BCS and prostate cancer survivors (PCS) ${ }^{34}$ because they often need androgen deprivation therapy. This indirectly affects the process of bone formation and resorption, and can increase the risk of fracture in PCS by up to five times compared to healthy men ${ }^{34}$. In BCS, the consequences of treatment on bone mineral density (BMD) may appear as of chemotherapy ${ }^{34}$. Osteoporosis means a loss of independence for older subjects and, of course, both increases the risk of fracture and impairs QoL ${ }^{32}$.

It has been confirmed that regular exercise reduces the risk of bone problems in PCS 34 . It is also known that increased lower limb strength prevents loss of muscle mass, reduces fat percentage increases during treatment ${ }^{29}$, and decreases the level of CRF in $\mathrm{BCS}^{35}$. Resistance training (RT) can, therefore, be an effective tool for PCS with androgen deprivation, due to its effects on muscle function, lean mass, and BMD ${ }^{15}$. The effectiveness of programmes that include impact and resistance training for the bone health of BCS has also been demonstrated ${ }^{36}$.

\section{Pain}

Pain in cancer patients can be basal ${ }^{37}$, appear suddenly, or be caused by neuropathic problems $s^{37-40}$ due to nerve compression caused by infiltration of the tumour or treatment toxicity ${ }^{39}$. It is considered a contributing factor to the development of $\mathrm{CRF}^{3}$ because it affects the patient's appetite, sleep quality, treatment adherence, mood $^{38}$, and level of activity to such an extent as to produce kinesiophobia ${ }^{41}$.

Although pain hinders PE adherence ${ }^{42}$, regular physical activity is known to help relieve it in various diseases, including those involving chronic pain ${ }^{42,43}$. Though different analgesia pathways are associated with exercise ${ }^{43}$, it is held that the effects achieved are proportionally related to the length and intensity of the exercise, and the isometric contractions ${ }^{43}$ associated with the modulation of the nervous system with respect to pain ${ }^{42}$.

In BCS, it has been observed that combined PE protocols (aerobic, resistance, and flexibility) ${ }^{44}$, Pilates ${ }^{45}$, Qigong ${ }^{46}$, specific exercises mobilising the arm on the affected side ${ }^{47}$, and simply a higher level of physical activity (even while under treatment ${ }^{48}$ reduce the intensity of pain and its impact on daily life. Similarly, lumbopelvic stabilisation exercises in colon cancer survivors can lead to improvements in pain perception, CRF, and mood 49 .

\section{Nutritional disturbances}

- Malnutrition: The presence of a tumour increases protein catabolism, lipolysis, insulin resistance, and energy expenditure in $\mathrm{CS}^{28}$. We also know that when the digestive system is affected or when patients are undergoing treatment, caloric intake falls ${ }^{2,28}$. If malnutrition ensues, the competition between the tumour and healthy cells for nutrients triggers hypermetabolism, leading to loss of efficiency in replenishing ATP and reducing the level of complete blood protein ${ }^{30}$. Malnutrition has consequences related to CRF: dysfunctional breathing patterns due to respiratory muscle atrophy, inactivity as a result of reduced functional capacity, heart muscle disorders, reduced glomerular filtration, depression, increased toxicity of the treatments ${ }^{28}$, and damage to the peripheral nervous system ${ }^{50}$. Anaemia ${ }^{31,51}$, cachexia $2,28,30,31$, and electrolyte imbalances ${ }^{28}$ may also develop. Finally, vitamin D deficiency influences the intensity of muscle pain and arthralgia, typical of hormonal treatment with aromatase inhibitors in $\mathrm{BCS}^{52}$, while iron deficiency is associated with restless legs syndrome $\mathrm{e}^{53}$, related to $C \mathrm{RF}^{3}$.

- Electrolyte imbalances: The most common alterations in CS are decreases in sodium and magnesium, and increases in potassium, 
phosphates, and calcium ${ }^{54}$. Chemotherapy, however, especially with cisplatin, can reduce the levels of all the minerals mentioned ${ }^{55}$. Some of the consequences of these imbalances affect CRF. Magnesium deficiency has a negative effect on fatigue, neuromuscular excitability ${ }^{55}$, cardiovascular health, energy production in cells, and inflammatory response ${ }^{56}$. Hyponatremia causes fatigue, cognitive impairment and, in severe cases, pulmonary oedema and increased risk of bone fracture ${ }^{54}$. Finally, hypercalcemia increases bone resorption and affects bone health ${ }^{55}$.

On this point, the positive effect of combined exercise and nutrition protocols for improving CRF in PCS ${ }^{57}$ and maintaining muscle mass in $\mathrm{BCS}^{58}$ has been reported. However, there is no evidence that PE might influence appetite in $\mathrm{CS}^{59}$.

\section{Stress, anxiety and depression}

Some authors suggest that depression predisposes patients to chronic fatigue and that it shares a common aetiology with CRF². Psychoemotional health, which is highly variable between patients, influences the level of fatigue ${ }^{1,60}$; to such an extent that there are studies which suggest that interventions to treat psychological and emotional disturbances could reduce its intensity ${ }^{60}$. Depression also affects adherence to medical treatment, particularly hormone therapy in BCS, with the consequences this might have on a patient's prognosis ${ }^{61}$.

The effectiveness of PE to improve the emotional state of CS is recognised by the National Comprehensive Cancer Network (NCCN) for its ability to reduce anxiety, perceived stress, and cortisol release ${ }^{62}$. Improvements in psycho-emotional health during chemotherapy in BCS are also greater when physical and psychological interventions are combined, especially when the physical interventions are supervised ${ }^{63}$. Specifically, aerobic exercise interventions (AE) ${ }^{12}$ and yoga ${ }^{64}$ reduce emotional symptoms in BCS although no significant improvements in physiological parameters have been observed through yoga ${ }^{64}$.

\section{Sleep problems}

Commonly associated with emotional issues ${ }^{4}$, insomnia, daytime sleepiness, and night-time awakening are directly related to fatigue in $\mathrm{CS}^{1,9}$. They are produced in part by disruption of the natural circadian cycle, which leads, precisely, to increased susceptibility to emotional disorders ${ }^{2}$. They are also the result of serotonin dysregulation and HPA-axis dysfunction, due to the increase in cortisol, which negatively influences non-REM sleep ${ }^{2}$. Finally, the increased level of cytokines due to chronic inflammation in $\mathrm{CS}^{65}$ also influences CRF, given their effect on daytime sleepiness, narcolepsy, and idiopathic insomnia². In the case of head and neck CS, radiotherapy favours the onset of sleep apnoea, although the relationship between this sequela and CRF could be due to a higher level of cytokines ${ }^{65}$.

Sleep problems, together with pain and CRF, significantly predict the functional decline of $\mathrm{CS}^{66,67}$, and although not all the research conducted has found a correlation between PE and improved quality of sleep, bene- fits have been confirmed in BCS, especially after treatment ${ }^{68}$. Although more research is needed, the moderate $A E$ protocols tested with $\mathrm{CS}^{69,70}$ and the RT protocols tested with BCS during radiotherapy have shown clear benefits regarding this problem compared to relaxation protocols $\mathrm{s}^{71}$.

\section{Cytokine dysregulation}

Chronic inflammation causes different symptoms related to $\mathrm{CRF}^{2,72}$, such as anaemia, depression, and cachexia ${ }^{51}$. The most direct relationship between cytokines and fatigue is caused by the amounts of tumour necrosis factor (TNF) receptor 1 (STNF-r1), C-reactive protein (CRP), and interleukin IL-6, the latter being of greatest importance when it comes to symptoms such as sleep problems and depression in BCS 5,72. The AIS protein (Anaemia-Inducing Factor) secreted by cancer tissue depresses the production of erythrocytes and the immune capacity of healthy cells, causes endothelial damage, and increases vascular permeability and the leakage of clotting factors ${ }^{18}$, encouraging the development of anaemia. The AIS protein also stimulates lipolytic activity, playing a part in the development of anorexia and cachexia ${ }^{30}$.

The development of cachexia depends on catabolic and proinflammatory cytokines (IL-1, TNF- $\alpha$, IL-6) and anti-inflammatory cytokines (IL-4, IL-10 and IL-12), and their ability to stop or reverse the cachectic process $^{30}$. During exercise, muscle tissue is the main source of cytokine production. However, regular muscle contraction produces myokines (anti-inflammatory) both in muscle tissue and at more distant sites which could suppress proinflammatory activity, meaning that habitual training would reduce their plasma concentration ${ }^{9}$. In fact, more active people, with or without a history of cancer, have lower levels of inflammatory markers (especially TNF- $\alpha$, IL-6, and CPR) 6,9. $^{\circ}$.

Continued PE is known to cause changes in myokine production. On the one hand, the reduction in myostatin permits less inhibition of the mammalian target-of-rapamycin (mTOR), thereby allowing increased tissue synthesis, less insulin resistance, and a reduction in sarcopenia ${ }^{73}$. On the other, increased secretion of IL-6 due to increased muscle mass recruitment and exercise intensity and duration induces a better response of anti-inflammatory cytokines such as IL-1Ra, IL-10, and STNF-R, and inhibits the effects of TNF- $\alpha^{73}$.

The release of pro-inflammatory cytokines during exercise, therefore, would be balanced by the production of anti-inflammatory cytokines and inflammatory response inhibitors ${ }^{9}$. Although the exact mechanisms through which exercise reduces systemic inflammation are unknown, other contributing factors, such as reduced body weight, increased insulin sensitivity, and improved endothelial function, have been suggested ${ }^{9}$, not only at a general level but also in relation to $\mathrm{CRF}^{72,74}$

\section{Anaemia}

According to the NCCN, anaemia is one of the CRF factors which may be treatable $e^{2,75,76}$. Although it depends on the type of cancer and stage, its prevalence is very high, reaching $30-80 \%$ of patients ${ }^{77}$. It may result from nutritional problems, erythropoiesis inhibition ${ }^{2}$, the 


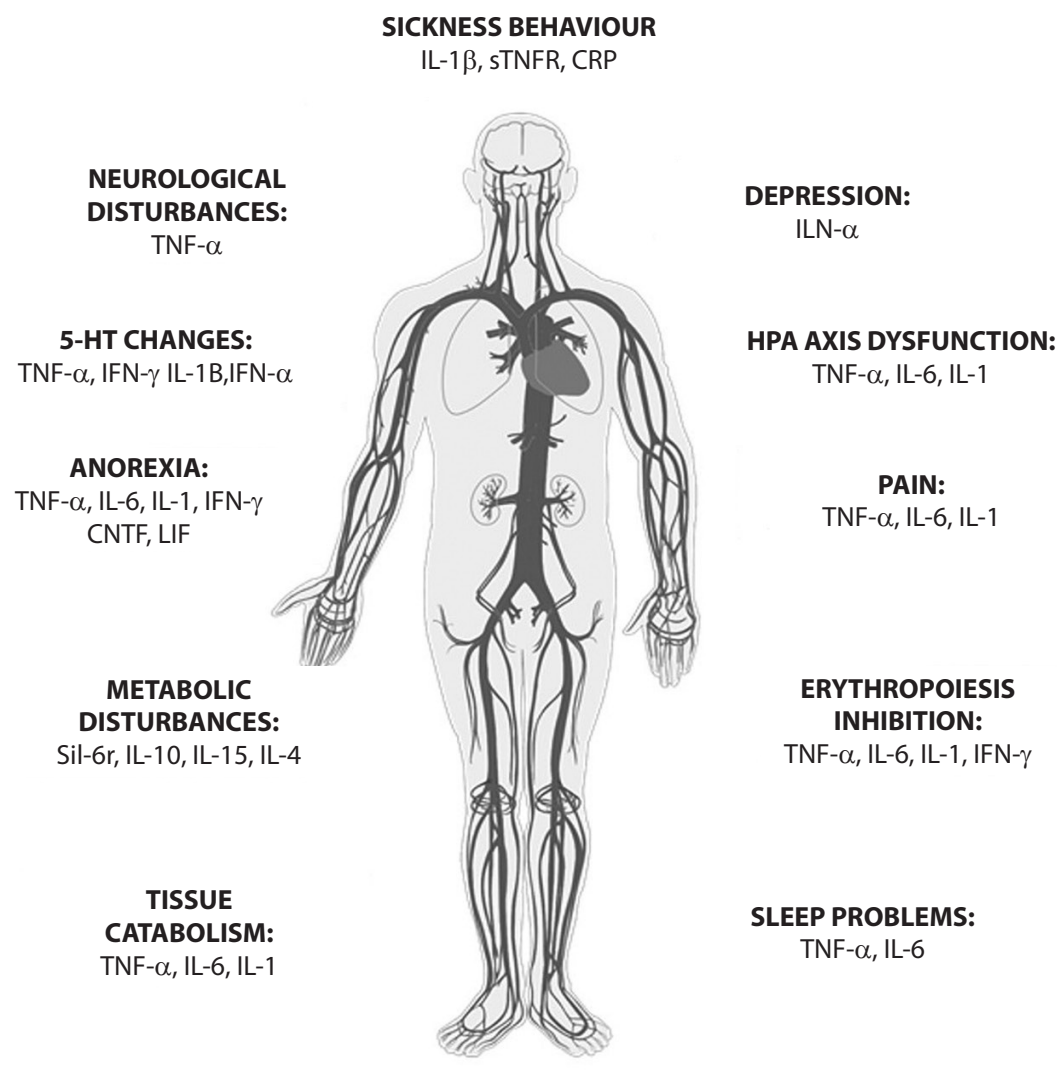

progression of the disease, or the treatment applied ${ }^{78}$. Although in some cases it can cause dyspnoea on exertion, chest pain, tachycardia, depression, anorexia, and sleep disturbances ${ }^{78}$, anaemia chiefly manifests as fatigue ${ }^{76.78}$. Additionally, it is important to consider that in some CS, it affects QoL and is associated with a worse prognosis and less effective treatment ${ }^{78}$.

Treatment with erythropoiesis-stimulating agents s1,76,77 $^{\text {or packed }}$ red blood cell transfusions ${ }^{76}$ yields positive results in terms of patient energy levels ${ }^{75}$, haemoglobin concentration, QoL, and prognosis ${ }^{78}$, although, of course, such treatment entails certain risks ${ }^{76}$. There is, therefore, evidence to suggest that QoL improves when the haemoglobin value improves ${ }^{78}$.

$P E$ in the case of anaemia would, therefore, be effective because it stimulates the production of erythrocytes ${ }^{9}$. Specifically, moderateintensity $\mathrm{AE}$, as occurs in healthy populations, increases blood volume through an early increase in plasma volume and a later increase in erythrocyte volume, normalising the haematocrit ${ }^{10.79}$. This not only improves oxygen transport (by increasing the total haemoglobin mass) but also improves cardiac output by increasing preload during diastole ${ }^{10}$, both fundamental in reducing CRF. However, if the anaemia is severe $(\mathrm{Hb}$ $<6 \mathrm{~g} / \mathrm{dL}$ ), it is advisable to put off exercise until it improves ${ }^{50}$, although patients can still perform daily life activities.

\section{Alterations in muscle metabolism}

There are several theories about the relationship between muscle metabolism and CRF which could explain, at least in part, the feeling of tiredness that patients describe ${ }^{2}$. One is ATP dysregulation, produced by the damage that the cancer or its treatment causes to the sarcoplasmic reticulum of cells, which increases intracellular calcium levels. This phenomenon has several possible consequences: lower protein synthesis; alterations in calcium release, and reduced calcium sensitivity of actin and myosin ${ }^{31}$. Together with this, most tumours degenerate the muscle tissue, leading to tissue loss (cachexia) and different alterations in the metabolism of its nutrients ${ }^{30}$. 
In this case, it has been observed that CS have less muscle strength than healthy subjects and that those with greater muscular strength are those with lower levels of $\mathrm{CRF}^{6}$. Therefore, it would appear that RT could improve muscle strength and function in $\mathrm{CS}^{6}$ by improving motor unit synchronisation, central nervous system activity, and motor neuron excitability ${ }^{44}$. AE, meanwhile, produces an increase in mitochondrial volume, density, and enzyme activity, which changes muscle morphology towards a phenotype which is more oxidative and, therefore, better able to synthesise ATP ${ }^{10}$.

\section{Treatments}

Each treatment applied can influence the onset of symptoms related to CRF (Table 1). It is known that the prevalence and duration of CRF is greater in patients who have undergone chemotherapy compared to those who have not ${ }^{80}$; the effects of radiotherapy on vital organs, sleep disorders, and hot flashes are widely described; and arthralgias are specific to hormonal treatments.

Increases in cytokine levels are considered one of the most determining factors for $\mathrm{CRF}$ as a result of treatment ${ }^{2,9}$. Analgesics or medication for comorbidities, such as $\beta$-blockers, antidepressants, or antiemetics, can also contribute to increases in the perception of fatigue'.

Among the effects of treatment directly related to CRF, it is found that:

- Surgery may compromise the nutritional status of patient ${ }^{28}$ and damage peripheral or muscle nerves, favouring the onset of pain ${ }^{23,81}$.

- Chemotherapy increases the risk of developing heart disease ${ }^{12,19,82,}$ pulmonary toxicity ${ }^{83}$; and ovarian failure, which accelerates bone loss in $\mathrm{BCS}^{24}$, and reduces the protective effect of oestrogen on cytokines ${ }^{52}$. It can also cause nervous disturbances which affect muscle force-generating capacity, initiating atrophy and functional decline ${ }^{12}$. Finally, it affects the digestive system, which has nutritional consequences ${ }^{23}$.

- Radiotherapy is also related to heart disease ${ }^{13,18}$, lung damage ${ }^{22}$, nerve damage, due to its effects on blood vessels and tissue fibrosis $^{81}$, anaemia ${ }^{78}$, and nutritional disturbances ${ }^{28}$.

- Finally, hormonal treatment with tamoxifen increases the risk of cardiovascular disease ${ }^{13}$, pulmonary toxicity, and hot flashes ${ }^{84,85}$. When aromatase inhibitors are used, there is a higher incidence of hypercholesterolemia ${ }^{13}$ (and, therefore, a greater risk of myocardial infarction ${ }^{86}$ ), joint pain, and increased bone loss and fracture ris ${ }^{52}$.

Taking certain considerations into account before planning the training programme ${ }^{14}, \mathrm{PE}$, even high-intensity exercise ${ }^{35,87}$, during chemotherapy has proven to be both safe and beneficial for cancer patients ${ }^{14,24,88}$. We also know that exercise induces the release of anti-inflammatory cytokines ${ }^{9}$, and various studies report improvements in cardiorespiratory level ${ }^{13,14}$, functionality ${ }^{14,89}$, muscle strength, fatigue ${ }^{14}$, body composition, and Qo ${ }^{89}$.

During radiotherapy, the effect of exercise on CRF is equally significant; interventions which centred exclusively on resistance in $\mathrm{BCS}^{90}$ and $P C S^{91}$ reduced the level of fatigue or prevented the decline that the subjects in the control groups suffered ${ }^{90,91}$.

\section{Hypothalamic-pituitary-adrenal (HPA) axis dysfunction}

Cancer and/or its treatment have a direct effect on the HPA axis, altering the release of cortisol $^{2}$ and androgens ${ }^{51}$. For example, lower decreases in cortisol levels during the day and high concentrations at night ${ }^{6}$ have been observed in breast and ovarian CS suffering from $\mathrm{CRF}$, and low testosterone levels related to fatigue have been observed in male $\mathrm{CS}^{75}$. Cortisol is also released in situations of psychological or

Table 1. Side effects of the treatments associated with cancer-related fatigue.

\begin{tabular}{lcc} 
& Oncological T. & Analgesic T. \\
\hline Heart condition & $\mathrm{CT}, \mathrm{RT}, \mathrm{TX} \& \mathrm{Al}$ & \\
Lung condition & $\mathrm{CT}, \mathrm{RT} \& \mathrm{TX}$ & Buprenorphine, morphine \& oxycodone \\
Nutritional disturbances & $\mathrm{S}, \mathrm{CT}, \mathrm{RT}$ & Oxycodone \\
Anaemia & $\mathrm{CT}, \mathrm{RT}$ & Tramadol \\
Mood swings & $\mathrm{CT}, \mathrm{RT}$ & \\
Liver damage & $\mathrm{S}, \mathrm{CT}, \mathrm{RT}$ & Oxycodone \& tramadol \\
Nerve damage & $\mathrm{CT}, \mathrm{RT}$ & Corticosteroids \& oxycodone \\
Kidney damage & $\mathrm{CT}$ & Morphine \& paracetamol \\
Fatigue & $\mathrm{CT}$ & \\
Insomnia & & \\
Kidney failure & $\mathrm{CT}$ & Anticonvulsants \\
Loss of muscle contractility & $\mathrm{CT}, \mathrm{Al}$ & Codeine, oxycodone \& tramadol \\
Bone loss & $\mathrm{TX}$ & Anticonvulsants \\
Vasomotor symptoms & & \\
Drowsiness & & \\
\hline
\end{tabular}

S: surgery; CT, chemotherapy; RT, radiotherapy; TX: tamoxifen (hormone treatment); Al: aromatase inhibitors (hormone treatment). 
physical stress ${ }^{2}$, but when stress becomes chronic, the production of proinflammatory cytokines increases and the functioning of the HPA axis is disrupted, reducing the release of cortisol and leading to symptoms compatible with $\mathrm{CRF}^{31}$.

Based on the research conducted, we know that the hormone release which takes place in healthy subjects during $A E$ could be altered in $\mathrm{BCS}^{92}$, it having been observed that the reduction in cortisol that PE produces is less pronounced in BCS compared to healthy women following a single session of moderate-intensity $A E^{92}$. We also know that there is no significant difference in cortisol levels between active and inactive $\mathrm{BCS}^{93}$. However, interference with the endocrine system caused by medication, sleep disturbance, psychological stress, and other factors means it is not possible to clearly describe the relationship between PE and cortisol, and further research into the subject is needed ${ }^{93}$.

\section{Serotonin dysregulation}

Serotonin (5-HT) regulates processes such as the circadian cycle, mood, pain, appetite, and cardiovascular and muscle functions ${ }^{2}$, processes which influence the intensity of $\mathrm{CRF}^{3}$. It has been described that in cancer patients, the increase in serotonin in the brain appears to decrease the nerve impulse to the muscle fibres ${ }^{2,3}$ and affects vagal afferent nerve activation, reducing the ability to carry out PE². The HPA axis is also directly affected by serotonin, with an increased release of corticotropin releasing hormone $(\mathrm{CRH})$, antidiuretic hormone $(\mathrm{ADH})$, and adrenocorticotropic hormone $(\mathrm{ACTH})^{2}$.

When healthy subjects perform PE, two mechanisms influence the increase in brain serotonin content and, consequently, the acute increase in fatigue ${ }^{94}$. Firstly, the depletion of glycogen reserves (should it occur), and secondly, the increase in the brain of the concentration of tryptophan, the precursor of 5-HT synthesis ${ }^{94}$. However, decreases in cortisol and serotonin have been reported in older female BCS after 12 weeks of AE (four weekly walking sessions), with a consequent improvement in sleep quality, but not in the level of CRF ${ }^{95}$. Even so, it is not known whether exercise could normalise the metabolism of serotonin in CS in the long term ${ }^{6}$.

\section{Vagal afferent nerve activation}

It has been studied that a healthy vagus nerve could inhibit the inflammation caused by cancer and that its activity, reflected in the basal heart rhythm, is associated with the prognosis of various types of cancer ${ }^{96}$. For example, a high basal heart rhythm and recovery heart rate (HR rec) are associated with a worse prognosis for people who have been operated on for lung cancer ${ }^{97}$. When there is inflammation, caused by the disease and its treatment, a peripheral release of cytokines occurs, activating vagal afferent nerves signals. This leads, among other things, to suppression of somatic muscle activity, sickness behaviour2,31, and changes in the hypothalamus ${ }^{31}$.

It is known that AE improves the aerobic capacity of cancer patients, their $\mathrm{HR}_{\mathrm{rec}}$ and autonomic control of cardiac muscle both during and af- ter treatment, especially in patients with lesser cardiovascular capacity ${ }^{98}$. Although these results are not reflected in the level of CRF, improved vagal tone may also reduce the risk of cardiac arrhythmias, which could have a positive impact on the survival of $\mathrm{CS}^{98}$.

\section{Vasomotor symptoms: hot flashes}

Typical during menopause, these mainly affect survivors who have received hormone therapy, such as $\mathrm{BCS}^{99}$ and $\mathrm{PCS}^{100}$. They are considered fatigue triggers because they are a bothersome symptom which affects daily activities ${ }^{84}, \mathrm{QoL}^{84,101}$, treatment adherence ${ }^{101}$, and rest $84,101,102$, and may augment the perception of pain and fatigue ${ }^{84}$.

Although PE is beneficial for controlling hot flashes in healthy women ${ }^{103}$, it is generally advised that BCS avoid any increases in body temperature ${ }^{99}$. In these women, breathing exercises and progressive relaxation seem to be effective ways of reducing the frequency of this event ${ }^{100,104}$.

\section{Conclusions}

Having reviewed the triggers of CRF, it is possible not only to appreciate the complexity of this side effect but also to recognise that it presents a significant number of physiological alterations which also have effects on other processes and increase the risk of developing comorbidities. Similarly, it can be observed that there are fatigue triggers inherent in the disease and, from there, unavoidable triggers and other factors which could be tackled. In this light, it would be appropriate to assess the advisability of applying preventive therapies for CRF, such as physical exercise.

One of the conclusions of this review is that decreased activity and physical deconditioning are not only CRF triggers in themselves but that they are also greatly aggravated by a great many of the factors related to this side effect (Figure 1A). Perhaps the most important conclusion of this review is that physical exercise is capable of reversing these two factors (being directly related to them) and that it also has positive effects on many other CRF triggers.

This review also concludes which CRF triggers could be improved through physical exercise, either during or after treatment. In addition to improving CRF directly as the main outcome, there is evidence that physical exercise improves CRF through its positive effects on organ dysfunctions, musculoskeletal problems, pain, and the effects of treatment (Table 2). There is also evidence that physical exercise has positive effects on other triggers, such as psycho-emotional disturbances, sleep problems, cytokine dysregulation, alterations in muscle metabolism, sleep dysregulation, and vagal afferent nerve activation. The action of physical exercise on CRF in these cases would be indirect but equally effective in reducing their overall intensity. Only in three of the fifteen CRF triggers is there no evidence of physical exercise having a positive effect. 
Table 2. Effects of physical exercise on cancer-related fatigue triggers.

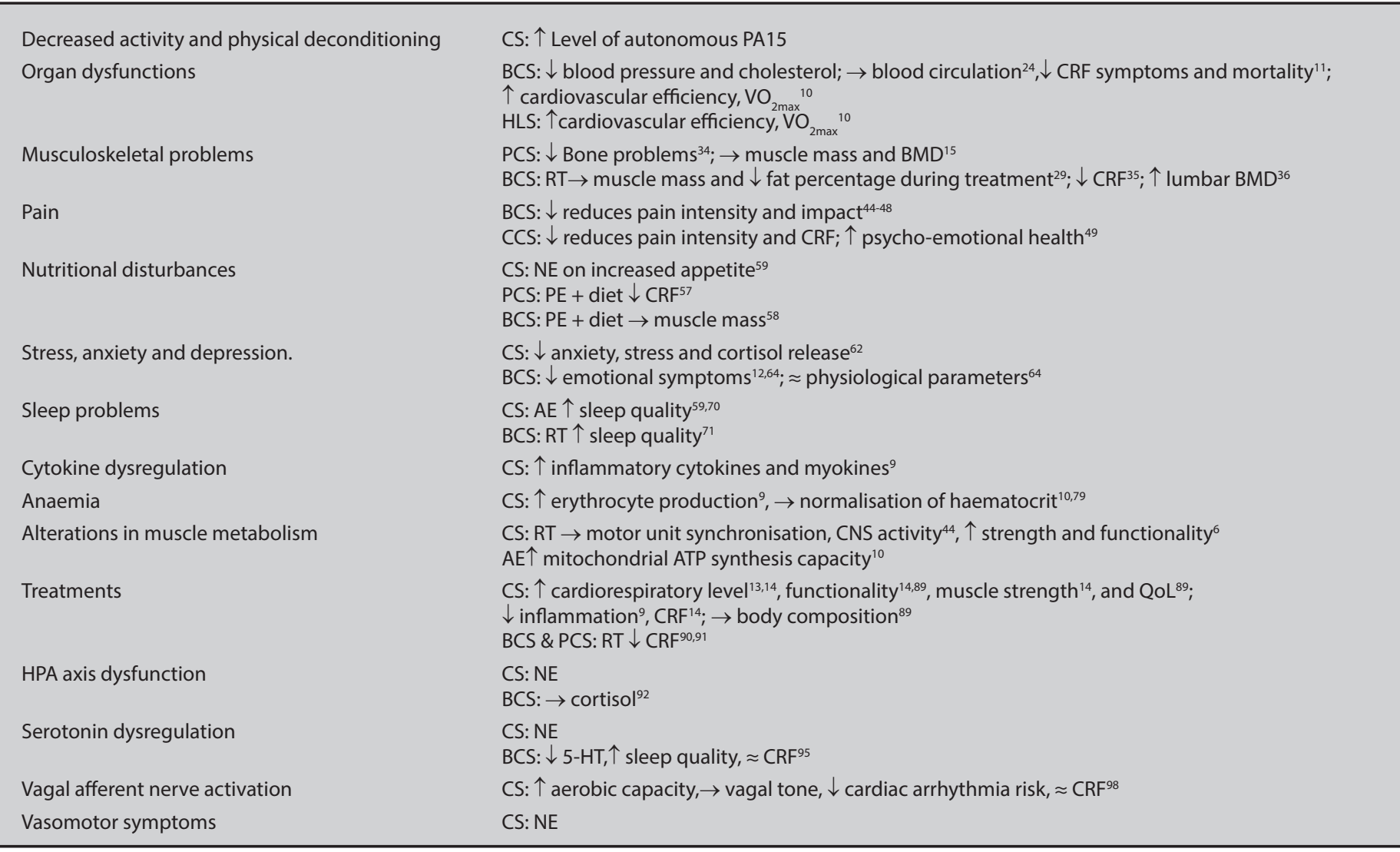

5-HT: serotonin; PA: physical activity; QoL: quality of life; BMD: bone mineral density; AE: aerobic exercise; PE: physical exercise; RT: resistance training; HPA: hypothalamic-pituitary-adrenal; CS: cancer survivors; CCS: colon cancer survivors; BCS: breast cancer survivors; PCS: prostate cancer survivors; HLS: Hodgkin lymphoma survivors; CNS: central nervous system.

$\rightarrow$ : effect on; $\uparrow$ : increases; $\downarrow$ : decreases; $\approx$ : does not change; NE: no evidence

In all, the findings of this review clearly describe the therapeutic value, at least as a coadjuvant, of physical exercise on the different side effects of cancer, making the inclusion of exercise programmes highly recommendable as preventive therapy for CRF.

\section{Conflict of Interests}

The authors do not declare any conflict of interests.

\section{Bibliography}

1. Berger A, Mooney K, Alvarez-Perez A, Breitbart W, Carpenter K, Cella D, et al. CancerRelated Fatigue, Version 2.2015. J Natl Compr Canc Netw. 2015;13:1012-39.

2. Ryan J, Carroll J, Ryan E, Mustian K, Fiscella K, Morrow G. Mechanisms of Cancer-Related Fatigue. Oncologist. 2007;12:22-34.

3. Ebede C, Jang Y, Escalante C. Cancer-Related Fatigue in Cancer Survivorship. Med Clin North Am. 2017;101:1085-97.

4. Servaes $P$, Verhagen $C$, Bleijenberg G. Fatigue in cancer patients during and after treatment: prevalence, correlates and interventions. Eur J Cancer. 2002;38:27-43.

5. Ji Y, Bo C, Xue X, Weng E, Gao G, Dai B, et al. Association of Inflammatory Cytokines With the Symptom Cluster of Pain, Fatigue, Depression, and Sleep Disturbance in Chinese Patients With Cancer. J Pain Symptom Manage. 2017;54:843-52.
6. Serdà i Ferrer B, Van Roekel E, Lynch B. The Role of Physical Activity in Managing Fatigue in Cancer Survivors. Curr Nutr Rep. 2018;7:59-69.

7. Kangas M, Bovbjerg D, Montgomery G. Cancer-related fatigue: A systematic and meta-analytic review of non-pharmacological therapies for cancer patients. Psychol Bull. 2008;134:700-41.

8. Alexander S, Minton O, Andrews P, Stone P. A comparison of the characteristics of disease-free breast cancer survivors with or without cancer-related fatigue syndrome. Eur J Cancer. 2009;45:384-92.

9. Mills R. Breast Cancer Survivors, Common Markers of Inflammation, and Exercise: A Narrative Review. Breast Cancer (Auckl). 2017;11:117822341774397.

10. Jones L, Eves N, Haykowsky M, Freedland S, Mackey J. Exercise intolerance in cancer and the role of exercise therapy to reverse dysfunction. Lancet Oncol. 2009; 10:598-605.

11. Scott J, Nilsen T, Gupta D, Jones L. Exercise Therapy and Cardiovascular Toxicity in Cancer. Circulation. 2018;137:1176-91.

12. Visovsky C. Muscle Strength, Body Composition, and Physical Activity in Women Receiving Chemotherapy for Breast Cancer. Integr Cancer Ther. 2006;5:183-91.

13. Mehta L, Watson K, Barac A, Beckie T, BittnerV, Cruz-Flores S, et al. Cardiovascular Disease and Breast Cancer: Where These Entities Intersect: A Scientific Statement From the American Heart Association. Circulation. 2018;137

14. Adamsen L, Quist M, Andersen C, Moller T, Herrstedt J, Kronborg D, et al. Effect of a multimodal high intensity exercise intervention in cancer patients undergoing chemotherapy: randomised controlled trial. BMJ. 2009;339:b3410-b3410.

15. Galvão D, Newton R. Review of Exercise Intervention Studies in Cancer Patients. J Clin Oncol. 2005;23:899-909. 
16. Clifford B, Mizrahi D, Sandler C, Barry B, Simar D, Wakefield C, et al. Barriers and facilitators of exercise experienced by cancer survivors: a mixed methods systematic review. Support Care Cancer. 2017;26:685-700

17. Yang D, Hausien O, Aqeel M, Klonis A, Foster J, Renshaw D, et al. Physical activity levels and barriers to exercise referral among patients with cancer. Patient Educ Couns. 2017;100:1402-7.

18. Giza D, lliescu G, Hassan S, Marmagkiolis K, lliescu C. Cancer as a Risk Factor for Cardiovascular Disease. Curr Oncol Rep. 2017;19.

19. Yu A, Jones L. Breast cancer treatment-associated cardiovascular toxicity and effects of exercise countermeasures. Cardiooncology. 2016;2.

20. Ponikowski P, Jankowska E. Patogenia y presentación clínica de la insuficiencia cardiaca aguda. Rev Esp Cardiol. 2015;68:331-7.

21. Howlader N, Noone A, Krapcho M, Miller D, Brest A, Yu M, et al. SEER Cancer Statistics Review, 1975-2017 (Internet). SEER. 2020. Disponible en https://seer.cancer.gov/ csr/1975_2017/

22. Verdú Rotellar J, Algara López M, Foro Arnalot P, DomínguezTarragona M, Blanch Mon A. Atención a los efectos secundarios de la radioterapia. Medifam. 2002;12.

23. Vega M, De Juan A, García A, López J, López C, López A, et al. Aspectos Psicológicos de la Toxicidad por Quimioterapia. Psicooncología. 2004;1:137-50.

24. Adraskela K, Veisaki E, Koutsilieris M, Philippou A. Physical Exercise Positively Influences Breast Cancer Evolution. Clin Breast Cancer. 2017;17:408-17.

25. Courneya KS, Sellar CM, Stevinson C, McNeely ML, Peddle CJ, Friedenreich CM, et al. Randomized controlled trial of the effects of aerobic exercise on physical functioning and quality of life in lymphoma patients. J Clin Oncol. 2009;27:4605-12.

26. Jones LW, Fels DR, West M, Allen JD, Broadwater G, Barry WT, et al. Modulation of circulating angiogenic factors and tumor biology by aerobic training in breast cancer patients receiving neoadjuvant chemotherapy. Cancer Prev Res (Phila). 2013; 6:925-37.

27. Courneya KS, Jones LW, Peddle CJ, Sellar CM, Reiman T, Joy AA, et al. Effects of aerobic exercise training in anemic cancer patients receiving darbepoetin alfa: a randomized controlled trial. Oncologist. 2008; 13:1012-20.

28. García-Luna P, Parejo Campos J, Aliaga Verdugo A, Pachón Ibáñez J, Serrano Aguayo P, Pereira Cunill J. Nutrición y cáncer. Nutr Hosp Suplementos. 2012;5:17-32.

29. Padilha C, Marinello P, Galvão D, Newton R, Borges F, Frajacomo F, et al. Evaluation of resistance training to improve muscular strength and body composition in cancer patients undergoing neoadjuvant and adjuvant therapy: a meta-analysis. $J$ Cancer Surviv. 2017;11:339-49.

30. Argíles J, Busquets S, López-Soriano F. Cytokines as mediators and targets for cancer cachexia. Cancer Treat Res. 2006;130:199-217.

31. O'Higgins C, Brady B, O'Connor B, Walsh D, Reilly R. The pathophysiology of cancerrelated fatigue: current controversies. Support Care Cancer. 2018;26:3353-64.

32. Miller C, Jones R, Piantadosi S, Abeloff M, Spivak J. Decreased erythropoietin response in patients with the anemia of cancer. N Engl J Med. 1990;322:1689-92.

33. Schmidt S, Rohm M, Herzig S, Berriel Diaz M. Cancer Cachexia: More Than Skeletal Muscle Wasting. Trends Cancer. 2018;4:849-60.

34. Handforth C, D'Oronzo S, Coleman R, Brown J. Cancer Treatment and Bone Health. Calcif Tissue Int. 2018;102:251-64.

35. Mijwel S, Backman M, Bolam K, Olofsson E, Norrbom J, Bergh J, et al. Highly favorable physiological responses to concurrent resistance and high-intensity interval training during chemotherapy: the OptiTrain breast cancer trial. Breast Cancer Res Treat. 2018;169:93-103.

36. Winters-Stone K, Dobek J, Nail L, Bennett J, Leo M, Naik A, et al. Strength training stops bone loss and builds muscle in postmenopausal breast cancer survivors: a randomized, controlled trial. Breast Cancer Res Treat. 2011;127:447-56.

37. Araujo A, Gómez M, Pascual J, Castañeda M, Pezonaga L, Borque J. Tratamiento del dolor en el paciente oncológico. Anales Sis San Navarra [Internet]. 2004;27(3):63-75. Disponible en: http://scielo.isciii.es/scielo.php?script=sci_arttext\&pid=\$113766272004000600007\&lng=es\&nrm=iso\%3E

38. Neufeld N, Elnahal S, Alvarez R. Cancer pain: a review of epidemiology, clinical quality and value impact. Future Oncol. 2017;13:833-41.

39. Jara C, del Barco S, Grávalos C, Hoyos S, Hernández B, Muñoz M, et al. SEOM clinical guideline for treatment of cancer pain (2017). Clin Trans Oncol. 2017;20:97-107.

40. Nahman-Averbuch H, Granovsky Y, Sprecher E, Steiner M, Tzuk-Shina T, Pud D, et al. Associations between autonomyc dysfunction and pain in chemotherapy-induced polyneuropathy. Eur J Pain. 2013;18:47-55

41. Van der Gucht E, Dams L, Meeus M, Devoogdt N, Beintema A, Penen F, et al. Kinesiophobia contributes to pain-related disability in breast cancer survivors: a cross-sectional study. Support Care Cancer.2020 Jan.

42. Lima L, Abner T, Sluka K. Does exercise increase or decrease pain? Central mechanisms underlying these two phenomena. J Physiol. 2017;595:4141-50.
43. Da Silva Santos R, Galdino G. Endogenous systems involved in exercise-induced analgesia. J Physiol Pharmacol. 2018;69:3-13.

44. Reis A, Pereira P, Diniz R, de Castro Filha J, dos Santos A, Ramallo B, et al. Effect of exercise on pain and functional capacity in breast cancer patients. Health Qual Life Outcomes. 2018;16.

45. Espíndula R, Nadas G, Rosa M, Foster C, Araújo F, Grande A. Pilates for breast cancer: A systematic review and meta-analysis. Rev Assoc Med Bras. 2017;63:1006-12.

46. Osypiuk K, Ligibel J, Giobbie-Hurder A, Vergara-Díaz G, Bonato P, Quinn R, et al. Qigong Mind-Body Exercise as a Biopsychosocial Therapy for Persistent Post-Surgical Pain in Breast Cancer: A Pilot Study. Integr Cancer Ther. 2020;19:1534735419893766.

47. De Groef A, Penen F, Dams L, Van der Gucht E, Nijs J, Meeus M. Best-Evidence Rehabilitation for Chronic Pain Part 2: Pain during and after Cancer Treatment. J Clin Med. 2019; 8:E979

48. Maridaki M, Papadopetraki A, Karagianni H, Koutsilieris M, Philippou A. The assessment and relationship between quality of life and physical activity levels in Greek breast cancer female patients under chemotherapy. Sports. 2020;8:32.

49. Cantarero-Villanueva I, Cuesta-Vargas A, Lozano-Lozano M, Fernández-Lao C, Fernández-Pérez A, Galiano-Castillo N. Changes in Pain and Muscle Architecture in Colon Cancer Survivors After a Lumbopelvic Exercise Program: A Secondary Analysis of a Randomized Controlled Trial. Pain Med. 2017;18:1366-76.

50. Rock C, Doyle C, Demark-Wahnefried W, Meyerhardt J, Courneya K, Schwartz A, et al. Nutrition and physical activity guidelines for cancer survivors. CA Cancer J Clin. 2012;62:242-74.

51. Neefjes E, van der Vorst M, Blauwhoff-Buskermolen S, Verheul H. Aiming for a Better Understanding and Management of Cancer-Related Fatigue. Oncologist. 2013;18:1135-43.

52. Niravath P. Aromatase inhibitor-induced arthralgia: a review. Ann Oncol. 2013;24:1443-9.

53. Venkateshiah S, loachimescu O. Restless Legs Syndrome. Crit Care Clin. 2015;31:459-72.

54. Pérez Romano N, Poch E. Hiponatremia en oncología. Nefrologia Sup Ext. 2011;2:61-6.

55. Oronsky B, Caroen S, Oronsky A, Dobalian V, Oronsky N, Lybeck M, et al. Electrolyte disorders with platinum-based chemotherapy: mechanisms, manifestations and management. Cancer Chemother Pharmacol. 2017;80:895-907.

56. Severino P, Netti L, Mariani M, Maraone A, D'Amato A, Scarpati R, et al. Prevention of Cardiovascular Disease: Screening for Magnesium Deficiency. Cardiol Res Pract. 2019;2019:1-10.

57. Baguley B, Bolam K, Wright O, SkinnerT. The Effect of Nutrition Therapy and Exercise on Cancer-Related Fatigue and Quality of Life in Men with Prostate Cancer: A Systematic Review. Nutrients. 2017;9:1003.

58. McDonald C, Bauer J, Capra S, Coll J. The muscle mass, omega-3, diet, exercise and lifestyle (MODEL) study - a randomised controlled trial for women who have completed breast cancer treatment. BMC Cancer. 2014;14.

59. Nakano J, Hashizume K, Fukushima T, Ueno K, Matsuura E, Ikio Y, et al. Effects of Aerobic and Resistance Exercises on Physical Symptoms in Cancer Patients: A Meta-analysis. Integr Cancer Ther. 2018;17:1048-58.

60. Hofman M, Ryan J, Figueroa-Moseley C, Jean-Pierre P, Morrow G. Cancer-Related Fatigue: The Scale of the Problem. Oncologist. 2007;12:4-10.

61. Souza B, Moraes J, Inocenti A, Santos M, Silva A, Miasso A. Women with breast cancer taking chemotherapy: depression symptoms and treatment adherence. Rev Lat Am Enfermagem. 2014;22:866-73.

62. Cuevas B, Hughes D, Parma D, Treviño-Whitaker R, Ghosh S, Li R, et al. Motivation, exercise, and stress in breast cancer survivors. Support Care Cancer. 2013;22:911-7.

63. Phillips K, Jim H, Small B, Tanvetyanon T, Roberts W, Jacobsen P. Effects of Self-directed Stress Management Training and Home-based Exercise on Stress Management Skills in Cancer Patients Receiving Chemotherapy. Stress Health. 2012;28:368-75.

64. Culos-Reed S, Carlson L, Daroux L, Hately-Aldous S. A pilot study of yoga for breast cancer survivors: physical and psychological benefits. Psychooncology. 2006;15:891-7.

65. Zhou J, Jolly S. Obstructive Sleep Apnea and Fatigue in Head and Neck Cancer Patients. Am J Clin Oncol. 2015;38:411-4.

66. Roscoe J, Kaufman M, Matteson-Rusby S, Palesh O, Ryan J, Kohli S, et al. Cancer-Related Fatigue and Sleep Disorders. Oncologist. 2007;12:35-42.

67. Ostacoli L, Saini A, Ferini-Strambi L, Castronovo V, Sguazzotti E, Picci R, et al. Restless legs syndrome and its relationship with anxiety, depression and quality of life in cancer patients undergoing chemotherapy. Qual Life Res. 2010;19:531-7.

68. Mercier J, Savard J, Bernard P. Exercise interventions to improve sleep in cancer patients: A systematic review and meta-analysis. Sleep Med Rev. 2017;36:43-56.

69. Tang M, Liou T, Lin C. Improving sleep quality for cancer patients: benefits of a homebased exercise intervention. Support Care Cancer. 2009;18:1329-39. 
70. Chiu H, Huang H, Chen P, Hou W, Tsai P. Walking Improves Sleep in Individuals With Cancer: A Meta-Analysis of Randomized, Controlled Trials. Oncol Nurs Forum. 2015;42:E54-E62.

71. Steindorf K, Wiskemann J, Ulrich C, Schmidt M. Effects of exercise on sleep problems in breast cancer patients receiving radiotherapy: a randomized clinical trial. Breast Cancer Res Treat. 2017;162:489-99.

72. LaVoy E, Fagundes C, Dantzer R. Exercise, inflammation, and fatigue in cancer survivors, Exerc Immunol Rev.2016;22:82-93.

73. Fiuza-Luces C, Garatachea N, Berger NA, Lucia A. Exercise is the real polypill. Physiology (Bethesda). 2013;28:330-58.

74. Himbert C, Ose J, Lin T, Warby CA, Gigic B, Steindorf K, et al. Inflammation and angiogenesis related biomarkers are correlated with cancer-related fatigue in colorectal cancer patients: Results from the ColoCare Study. Eur J Cancer Care (Engl). 2019;28:e13055.

75. Shafqat A, Einhorn L, Hanna N, Sledge G, Hanna A, Juliar B, et al. Screening studies for fatigue and laboratory correlates in cancer patients undergoing treatment + . Ann Oncol. 2005;16:1545-50.

76. Rodgers G, Becker P, Blinder M, Cella D, Chanan-Khan A, Cleeland C, et al. Cancer- and Chemotherapy-Induced Anemia. J Nat/ Compr Canc Netw. 2012;10:628-53.

77. Knight K, Wade S, Balducci L. Prevalence and outcomes of anemia in cancer: a systematic review of the literature. Am J Med. 2004;116:11-26.

78. Otón Sánchez C, Peñate González G, Otón Sánchez L. Eritropoyetina en la anemia del paciente oncológico. Luces y sombras. Med Clin. 2005;124:186-95.

79. Mohamady $\mathrm{H}$, Elsisi $\mathrm{H}$, Aneis $\mathrm{Y}$. Impact of moderate intensity aerobic exercise on chemotherapy-induced anemia in elderly women with breast cancer: A randomized controlled clinical trial. J Adv Res. 2017;8:7-12

80. Jacobsen P, Hann D, Azzarello L, Horton J, Balducci L, Lyman G. Fatigue in women receiving adjuvant chemotherapy for breast cancer: characteristics, couse and correlates. J Pain Symptom Manage. 1999;18.

81. Grisold W, Grisold A, Löscher W. Neuromuscular complications in cancer. J Neurol Sci. 2016:367:184-202

82. Navarrete Hurtado S, Castellanos García A, Chaparro Sanabria A. Cardiotoxicidad por quimioterapia Un enfoque práctico para el clínico. Insuf Card. 2011;6(3).

83. Carrión Valero F, Marín Pardo J. Toxicidad pulmonar por fármacos. Arch Bronconeumol. 1999;35:550-9.

84. Chang H, Jotwani A, Lai Y, Jensen M, Syrjala K, Fann J, et al. Hot flashes in breast cancer survivors: Frequency, severity and impact. Breast. 2016;27:116-21.

85. Lee C, Fox P, Balakrishnar B, Balleine R, Gao B, Provan P, et al. Tamoxifen-induced severe hot flashes and endoxifen levels: is dose reduction a safe and effective strategy?. Breast. 2019;46:52-7.

86. Abdel-Qadir H, Amir E, Fischer H, Fu L, Austin P, Harvey $\mathrm{P}$, et al. The risk of myocardial infarction with aromatase inhibitors relative to tamoxifen in post-menopausal women with early stage breast cancer. Eur J Cancer. 2016;68:11-21.

87. Mijwel S, Backman M, Bolam K, Jervaeus A, Sundberg C, Margolin S, et al. Adding high-intensity interval training to conventional training modalities: optimizing healthrelated outcomes during chemotherapy for breast cancer: the OptiTrain randomized controlled trial. Breast Cancer Res Treat. 2017;168:79-93.

88. Schmitz K, Courneya K, Matthews C, Demark-Wahnefried W, Galvão D, Pinto B, et al. American College of Sports Medicine Roundtable on Exercise Guidelines for Cancer Survivors. Med Sci Sports Exerc. 2010:42:1409-26.
89. Campbell A, Mutrie N, White F, McGuire F, Kearney N. A pilot study of a supervised group exercise programme as a rehabilitation treatment for women with breast cancer receiving adjuvant treatment. Eur J Oncol Nurs. 2005;9:56-63.

90. Wiskemann J, Schmidt M, Klassen O, Debus J, Ulrich C, Potthoff K, et al. Effects of 12 week resistance training during radiotherapy in breast cancer patients. Scand J Med Sci Sports. 2016;27:1500-10

91. Hojan K, Kwiatkowska-Borowczyk E, Leporowska E, Gòreck M, Ozga- Majchrzak O, Milecki T, et al. Physical exercise for functional capacity, blood immune function, fatigue, and quality of life in high-risk prostate cancer patients during radiotherapy: a prospective, randomized clinical study. Eur J Phys Rehabil Med 2016;52:489-501.

92. Evans E, Hackney A, Pebole M, McMurray R, Muss H, Deal A, et al. Adrenal Hormone and Metabolic Biomarker Responses to 30 min of Intermittent Cycling Exercise in Breast Cancer Survivors. Int J Sports Med. 2016;37:921-9.

93. Lambert M, Brunet J, Couture-Lalande M, Bielajew C. Aerobic physical activity and salivary cortisol levels among women with a history of breast cancer. Complement Ther Med. 2019:42:12-8.

94. Meeusen R, Watson P, Hasegawa H, Roelands B, Piacentini M. Central Fatigue. Sports Med. 2006:36:881-909.

95. Payne J, Held J, Thorpe J, Shaw H. Effect of Exercise on biomarkers, fatigue, sleep disturbances and depressive symptoms in older woman with breast cancer receiving hormonal therapy. Oncol Nurs Forum. 2008;35:635-42.

96. Reijmen E, Vannucci L, De Couck M, De Grève J, Gidron Y. Therapeutic potential of the vagus nerve in cancer. Immunol Lett. 2018;202:38-43.

97. Ha D, Choi H, Zell K, Raymond D, Stephans K, Wang X, et al. Association of impaired heart rate recovery with cardiopulmonary complications after lung cancer resection surgery. J Thorac Cardiovasc Surg. 2015;149:1168-73.e3.

98. Niederer D, Vogt L, Gonzalez-Rivera J, Schmidt K, BanzerW. Heart rate recovery and aerobic endurance capacity in cancer survivors: interdependence and exercise-induced improvements. Support Care Cancer. 2015;23:3513-20.

99. Loprinzi C, Wolf S, Barton D, Laack N. Symptom management in premenopausa patients with breast cancer. Lancet Oncol. 2008;9:993-1001.

100. Challapalli A, Edwards S, Abel P, Mangar S. Evaluating the prevalence and predictive factors of vasomotor and psychological symptoms in prostate cancer patients receiving hormonal therapy: Results from a single institution experience. Clin Trans Radiat Oncol. 2018;10:29-35.

101. Hutton B, Yazdi F, Bordeleau L, Morgan S, Cameron C, Kanji S, et al. Comparison of physical interventions, behavioral interventions, natural health products, and pharmacologics to manage hot flashes in patients with breast or prostate cancer: protoco for a systematic review incorporating network meta-analyses. Syst Rev. 2015;4.

102. Leysen L, Lahousse A, Nijs J, Adriaenssens N, Mairesse O, Ivakhnov S, et al. Prevalence and risk factors of sleep disturbances in breast cancer survivors: systematic review and meta-analyses. Support Care Cancer. 2019;27:4401-33.

103. Gibson C, Matthews K, Thurston R. Daily physical activity and hot flashes in the Study of Women's Health Across the Nation (SWAN) Flashes Study. Fertil Steril. 2014;101:1110-6.

104. Kligman L, Younus J. Management of hot flashes in women with breast cancer. Cur Oncol. 2010;17. 